\title{
Molecular evidence reveals thyrotropin intervention enhances the risk of developing radioiodine-refractory differentiated thyroid carcinoma
}

Hilda Samimi ${ }^{1}$ and Vahid Haghpanah ${ }^{1,2^{*}(1)}$

\begin{abstract}
Radioiodine (RAI) is the mainstay of treatment for differentiated thyroid carcinoma (DTC) following total thyroidectomy. Nevertheless, about 5\% of patients with DTC are RAI-refractory (RAI-R). Understanding the molecular mechanisms associated with DTC during progression towards RAI-R DTC, including thyroid-stimulating hormone levels, may help to explain the pathophysiology of challenging RAI-R DTC clinical cases.
\end{abstract}

Keywords: Radioiodine refractory, Differentiated thyroid carcinoma, Thyrotropin, Sodium/iodide symporter, Thyroglobulin

\footnotetext{
*Correspondence: v.haghpanah@gmail.com; vhaghpanah@tums.ac.ir

${ }^{1}$ Endocrinology and Metabolism Research Center (EMRC), Endocrinology

and Metabolism Clinical Sciences Institute, Tehran University of Medical

Sciences, Tehran, Iran

Full list of author information is available at the end of the article
} to the material. If material is not included in the article's Creative Commons licence and your intended use is not permitted by statutory regulation or exceeds the permitted use, you will need to obtain permission directly from the copyright holder. To view a copy of this licence, visit http://creativecommons.org/licenses/by/4.0/. The Creative Commons Public Domain Dedication waiver (http://creativeco mmons.org/publicdomain/zero/1.0/) applies to the data made available in this article, unless otherwise stated in a credit line to the data. 


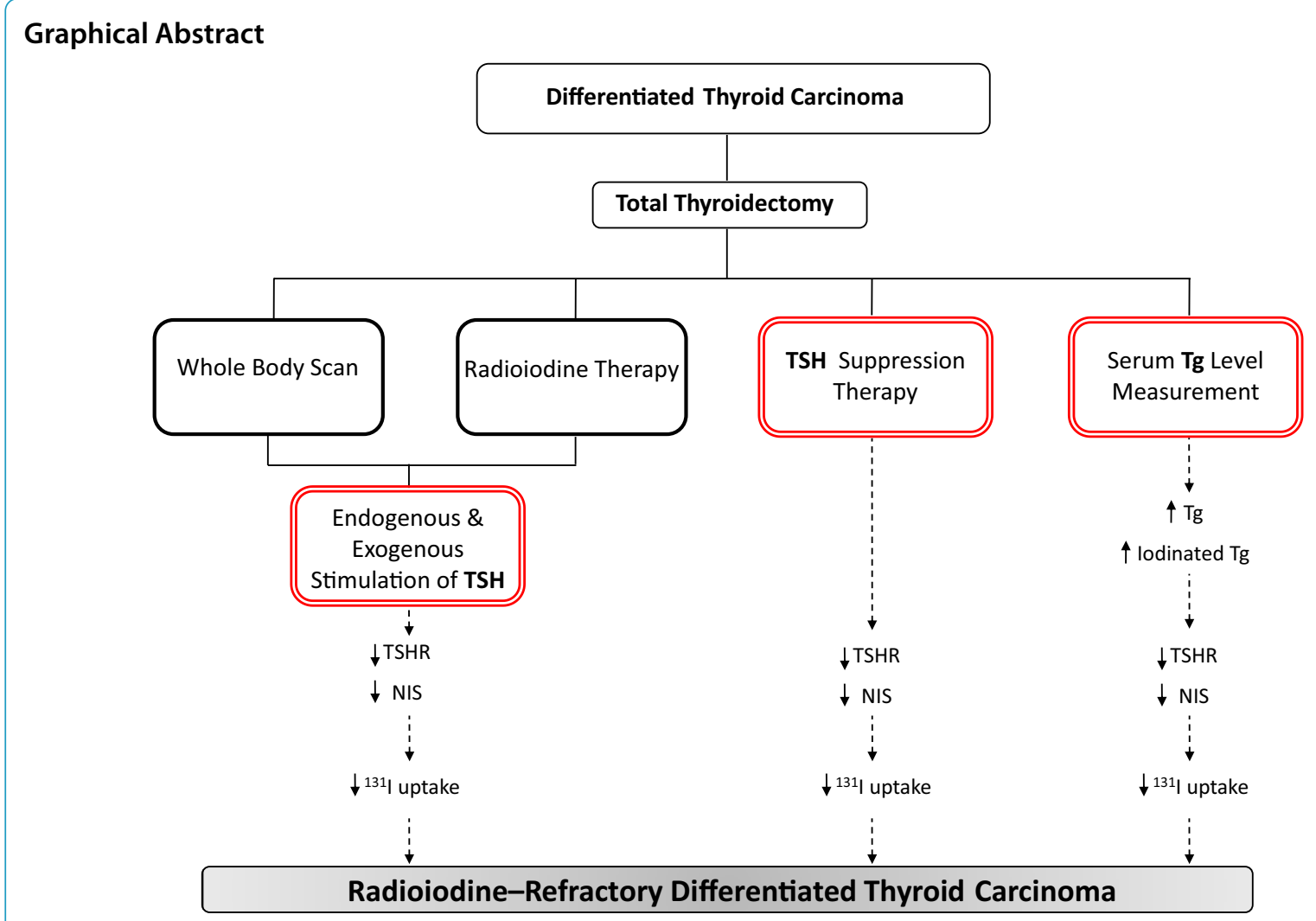

\section{Background}

Thyroid cancer is the most frequent endocrine malignancy and has the highest growing incidence rate between the other kinds of solid tumors in the United States [1]. Differentiated thyroid carcinoma (DTC) accounts for $85-95 \%$ of all thyroid cancers [2]. After total thyroidectomy, radioiodine (RAI) ablation followed by long-term suppression of thyroid-stimulating hormone (TSH) through thyroid hormone supplementation is the treatment plan for patients with DTC [3]. RAI is the mainstay of treatment for patients with DTC following total thyroidectomy. However, a small percentage of patients with recurrent DTC have tumors that do not concentrate ${ }^{131}$ I, resulting in RAI resistance, poor prognosis, and a clinical challenge for physicians and patients [4]. Understanding the biological mechanisms associated with DTC progression towards radioiodine-refractory (RAI-R) DTC may therefore be beneficial in providing an effective and appropriate plan for these cases.

In this paper, we aim to hypothesize and discuss the possible molecular association between TSH suppression therapy and thyroid hormone withdrawal before RAI therapy and whole body scan (WBS) as well as degree of iodinated thyroglobulin ( $\mathrm{Tg}$ ) with the increased risk of developing RAI-R DTC, by affecting the regulation of thyroid-stimulating hormone receptor (TSHR) and sodium/iodide $\left(\mathrm{Na}^{+} / \mathrm{I}^{-}\right)$symporter (NIS) expression as the main factor in ${ }^{131}$ I uptake.

TSH suppression therapy and risk of developing RAI-R DTC Previous studies have shown that TSH-mediated cAMP/ protein kinase A (cAMP/PKA) and phospholipase $\mathrm{C} /$ protein kinase $\mathrm{C}$ (PLC/PKC) signaling pathways are very important for the regulation of $T g, T S H R$, and NIS expression and consequently $\mathrm{I}^{-}$uptake and synthesis of thyroid hormones including triiodothyronine (T3) and thyroxine (T4) [5-9]. The concentration of TSH in the activation of each of these pathways is decisive. Activation of the PLC/PKC signaling pathway requires tenfold higher concentrations of TSH than those needed to activate cAMP/PKA pathway [10-12]. However, D'Arcangelo et al. showed based on the in vitro experiment that the concentrations of TSH from 0.01 to $10 \mathrm{mU} / \mathrm{L}$ can also activate this pathway in primary human thyrocytes [13]. Generally, the PLC/PKC signaling pathway inhibits differentiation of thyroid cells such as TSH-stimulated $\mathrm{I}^{-}$ uptake ability and cytoplasmic Tg mRNA accumulation [14] and regulates $\mathrm{I}^{-}$efflux and $\mathrm{Tg}$ iodination, while the cAMP/PKA pathway increases $\mathrm{I}^{-}$uptake, $T g$ and NIS expression, and thyroid differentiation [10, 15] (Fig. 1). 


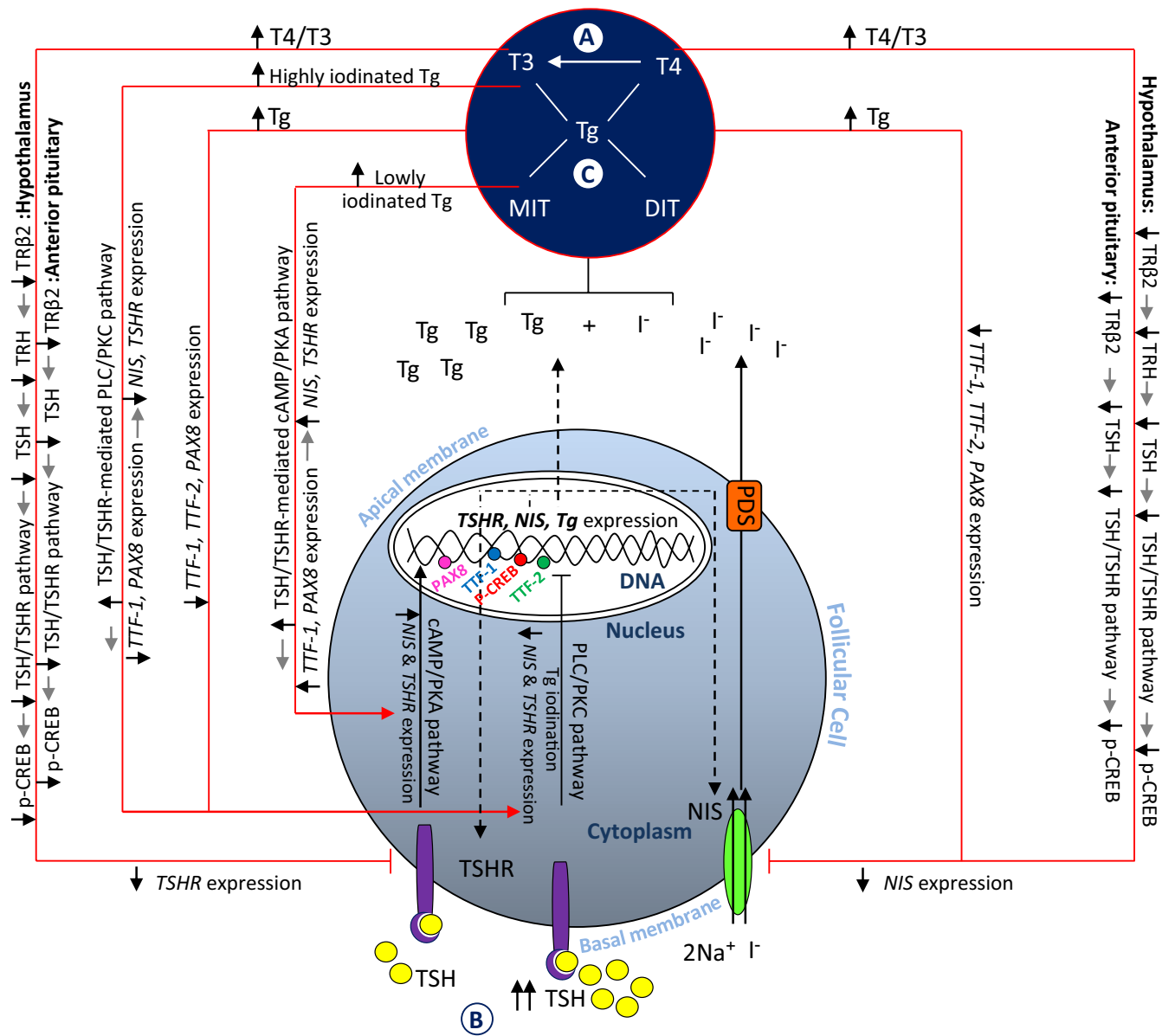

Fig. 1 Hypothesized molecular mechanisms of T4/T3 (A), TSH (B), and Tg (C) in developing RAI-R DTC. Abbreviations: DIT, di-iodotyrosine; I' , iodine; MIT, mono-iodotyrosine; $\mathrm{Na}^{+}$, sodium; NIS, sodium iodide symporter; PAX8, paired box 8; p-CREB, phospho-cAMP response element binding protein; PDS, pendrin; PKA, protein kinase A; PKC, protein kinase C; PLC, phospholipase C; T3, triiodothyronine; TR 32 , thyroid hormone receptor beta-2; T4, thyroxine; Tg, thyroglobulin; TRH, thyrotropin releasing hormone; TSH, thyroid-stimulating hormone; TSHR, thyroid-stimulating hormone receptor; TTF-1, thyroid transcription factor 1; TTF-2, thyroid transcription factor 2

Patients with DTC are given thyroid hormone supplementation after total thyroidectomy in order to suppress TSH. Thyroid hormone supplementation in doses which suppress serum TSH to below the normal levels (0.4$4.2 \mathrm{mU} / \mathrm{L}$ ) [16] may however cause permanent changes in the expression of thyroid-specific genes. At high T4/ T3 concentration, the expression of NIS and TSHR are likely downregulated due to decreased level of thyroid hormone receptor beta-2 (TR $\beta 2)$, thyrotropin releasing hormone (TRH), and TSH, via negative feedback loop between the thyroid gland and anterior pituitary and hypothalamus, as well as phospho-cAMP response element binding protein (p-CREB), as an important transcription factor for NIS upstream enhancer (NUE) and TSHR promoter (Fig. 1A) [7, 17, 18]. Therefore, following long-term TSH suppression therapy, NIS and TSHR expression may be indirectly reduced by epigenetic modifications due to a decrease in $\mathrm{p}-\mathrm{CREB}$, which probably causes permanent changes in the expression of NIS and TSHR genes to lower than normal levels in thyrocytes. Hence, thyroid hormone supplementation for TSH suppression may impair NIS and TSHR expression, ${ }^{131} \mathrm{I}$ uptake, and response to RAI therapy or WBS.

\section{Endogenous and exogenous stimulation of TSH and risk of developing RAI-R DTC}

Before WBS and RAI therapy, the serum concentration of TSH in patients with DTC should be raised above the normal range, either by thyroid hormone withdrawal or by recombinant human TSH, providing the necessary TSH concentration to stimulate the thyroid cells for sufficient RAI uptake. As mentioned above, TSH induces 
TSHR and NIS expression through the cAMP/PKA pathway and increases NIS transfer to the basal membrane of follicular cells. It is important to note that TSH increases TSHR in normal thyrocytes up to a certain limit, while high concentrations of TSH downregulates the expression of TSHR [9] and likely NIS genes (Fig. 1B). High TSH concentration, even in this short period, can possibly be a factor in decreasing NIS and TSHR expression at least at the molecular level, ${ }^{131}$ I uptake, and resistance to RAI therapy. Recently, Xiao et al. showed that determining the optimal level of TSH before ${ }^{131}$ I ablation can be clinically useful for achieving a better response to RAI therapy [19]. This clinical evidence can support the current hypothesis.

\section{Degree of iodinated Tg and risk of developing RAI-R DTC}

As mentioned above, TSH/TSHR signaling pathway regulates Tg iodination through PLC/PKC pathway [15]. In addition, TSH-mediated stimulation of thyroid follicular cells induces post-translational modifications of Tg molecules that are necessary for $\mathrm{Tg}$ iodination and increased hormonogenic potential of $\mathrm{Tg}$ [20]. Evidence has shown that the degree of $\mathrm{Tg}$ iodination in the follicular lumen can affect NIS [5, 6] and probably TSHR expression through activation of cAMP/PKA or PLC/PKC signaling pathways and regulation of thyroid-specific transcription factors, TTF-1 and PAX8 (Fig. 1C).

Serum Tg molecules include newly synthesized noniodinated Tg as well as iodinated Tg containing hormone residues, T3 and/or T4. Studies have shown that circulating $\mathrm{Tg}$ molecules may serve as the substrate for production of T3/T4 outside of thyroid gland [21-23]. Druetta et al. demonstrated that $\mathrm{Tg}$ released by metastatic DTC mostly, if not exclusively, is non-iodinated glycoprotein [21]. Although, serum Tg level measurement is used as a prognostic biomarker in predicting distant metastasis and recognizing RAI-R DTC, more studies are needed to determine the association between the degree of serum Tg iodination and its regulatory molecular mechanism on NIS and TSHR gene expression. In addition, studies have indicated that $\mathrm{Tg}$ accumulation at the follicular lumen may decrease NIS and TSHR expression and consequently $\mathrm{I}^{-}$uptake by autoregulating the expression of thyroid-specific transcription factors such as TTF-1, TTF-2, and PAX8 [8, 24] (Fig. 1C). Both mentioned mechanisms may occur in RAI-R DTC cases. The reduced expression of NIS and TSHR may lead to an impaired response to therapeutic and diagnostic RAI uptake.

\section{Conclusion}

Collectively, physiological disturbance of TSH, either when TSH has been suppressed or TSH increased to stimulate thyroid cells, may interfere with the molecular mechanisms referred to in some DTC patients with impaired RAI uptake. Monitoring of TSH levels during follow up could therefore lead to determination of the appropriate TSH cut-off and also TSH suppression or stimulation periods in DTC cases, thereby reducing the likelihood of RAI-R DTC. Moreover, finding the optimal TSH concentration may be more beneficial for patients with $B R A F^{\mathrm{V} 600 \mathrm{E}}$ and telomerase reverse transcriptase (TERT) promoter mutations that are more susceptible to resistance to RAI therapy [25].

Finally, more evidence about RAIR molecular mechanisms, mainly in relation to TSH physiology, can pave the way for identifying patients with increased risk of RAI-R DTC and provide more effective treatment for this challenging paradigm. Alternatively, having genetic and epigenetic patterns of DTC cases could help to predict susceptibility to RAI-R DTC.

\begin{abstract}
Abbreviations
CAMP: Cyclic adenosine monophosphate; DIT: Di-iodotyrosine; DTC: Differenti-

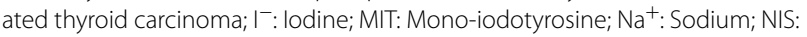
Sodium iodide symporter; NUE: NIS upstream enhancer; PAX8: Paired box 8; $\mathrm{p}$-CREB: Phospho-cAMP response element binding protein; PDS: Pendrin; PKA: Protein kinase A; PKC: Protein kinase C; PLC: Phospholipase C; RAl: Radioiodine; RAI-R: Radioiodine-refractory; T3: Triiodothyronine; T4: Thyroxine; TERT:Telomerase reverse transcriptase; Tg: Thyroglobulin; TRH: Thyrotropin releasing hormone; TSH: Thyroid-stimulating hormone; TSHR: Thyroid-stimulating hormone receptor; TSH 3 : Thyroid-stimulating hormone beta; TTF-1: Thyroid transcription factor 1;TTF-2: Thyroid transcription factor 2; WBS: Whole body scan.
\end{abstract}

\section{Acknowledgements \\ The authors are grateful to Dr. Sayed Mahmoud Sajjadi-Jazi, Dr. Mahmood Naderi and Dr. Ali Jalili for their helpful suggestions and advice. Also, the authors are thankful to Mr. Andrew Grimshaw for his English language com- ments on the final draft of the manuscript.}

\section{Authors' contributions}

$\mathrm{HS}$ and VH created the idea and discussed the concept. HS wrote the first draft of the manuscript. All authors have read and approved the final manuscript.

\section{Funding}

This research did not receive any specific grant from funding agencies in the public, commercial, or not-for-profit sectors.

Availability of data and materials

Not applicable.

\section{Declarations}

Ethics approval and consent to participate

Not applicable.

\section{Consent for publication}

Not applicable.

\section{Competing interests}

The authors declare that they have no conflict of interest.

\section{Author details}

${ }^{1}$ Endocrinology and Metabolism Research Center (EMRC), Endocrinology and Metabolism Clinical Sciences Institute, Tehran University of Medical Sciences, Tehran, Iran. ${ }^{2}$ Personalized Medicine Research Center, Endocrinology 
and Metabolism Clinical Sciences Institute, Tehran University of Medical Sciences, Tehran, Iran.

Received: 23 September 2021 Accepted: 23 January 2022

Published online: 03 February 2022

\section{References}

1. Jung CK, Little MP, Lubin JH, Brenner AV, Wells SA, Sigurdson AJ, et al. The increase in thyroid cancer incidence during the last four decades is accompanied by a high frequency of BRAF mutations and a sharp increase in RAS mutations. J Clin Endocrinol Metab. 2014;99(2):E276-85.

2. Fugazzola L, Elisei R, Fuhrer D, Jarzab B, Leboulleux S, Newbold K, et al. European Thyroid Association Guidelines for the treatment and followup of advanced radioiodine-refractory thyroid cancer. Eur Thyroid J. 2019:8(5):227-45.

3. Wang LY, Smith AW, Palmer FL, Tuttle RM, Mahrous A, Nixon IJ, et al. Thyrotropin suppression increases the risk of osteoporosis without decreasing recurrence in ATA low-and intermediate-risk patients with differentiated thyroid carcinoma. Thyroid. 2015;25(3):300-7.

4. Durante C, Haddy N, Baudin E, Leboulleux S, Hartl D, Travagli J, et al. Longterm outcome of 444 patients with distant metastases from papillary and follicular thyroid carcinoma: benefits and limits of radioiodine therapy. $J$ Clin Endocrinol Metab. 2006;91(8):2892-9.

5. Huang H, Shi Y, Liang B, Cai H, Cai Q. lodinated TG in thyroid follicles regulate TSH/TSHR signaling for NIS expression. Biol Trace Elem Res. 2017;180(2):206-13.

6. Huang H, Shi Y, Liang B, Cai H, Cai Q. lodinated TG in thyroid follicular lumen regulates TTF-1 and PAX8 expression via TSH/TSHR signaling pathway. J Cell Biochem. 2017;118(10):3444-51.

7. García-Jiménez C, Santisteban P.TSH signalling and cancer. Arq Bras Endocrinol Metabol. 2007;51(5):654-71.

8. Suzuki K, Lavaroni S, Mori A, Ohta M, Saito J, Pietrarelli M, et al. Autoregulation of thyroid-specific gene transcription by thyroglobulin. Proc Natl Acad Sci USA. 1998;95(14):8251-6.

9. Akamizu T, Ikuyama S, Saji M, Kosugi S, Kozak C, McBride OW, et al. Cloning, chromosomal assignment, and regulation of the rat thyrotropin receptor: expression of the gene is regulated by thyrotropin, agents that increase cAMP levels, and thyroid autoantibodies. Proc Natl Acad Sci USA. 1990;87(15):5677-81.

10. Rivas M, Santisteban P. TSH-activated signaling pathways in thyroid tumorigenesis. Mol Cell Endocrinol. 2003;213(1):31-45.

11. Yanagita Y, Okajima F, Sho K, Nagamachi Y, Kondo Y. An adenosine derivative cooperates with TSH and Graves' lgG to induce Ca2+ mobilization in single human thyroid cells. Mol Cell Endocrinol. 1996;118(1-2):47-56.

12. Laurent E, Mockel J, Van Sande J, Graff I, Dumont JE. Dual activation by thyrotropin of the phospholipase $\mathrm{C}$ and cyclic AMP cascades in human thyroid. Mol Cell Endocrinol. 1987;52(3):273-8.

13. D’Arcangelo D, Silletta MG, Di Francesco AL, Bonfitto N, Di Cerbo A, Falasca M, et al. Physiological concentrations of thyrotropin increase cytosolic calcium levels in primary cultures of human thyroid cells. J Clin Endocrinol Metab. 1995;80(4):1136-43.

14. Roger PP, Reuse S, Servais P, Van Heuverswyn B, Dumont JE. Stimulation of cell proliferation and inhibition of differentiation expression by tumorpromoting phorbol esters in dog thyroid cells in primary culture. Cancer Res. 1986;46(2):898-906.

15. Tuncel M. Thyroid stimulating hormone receptor. Mol Imaging Radionucl Ther. 2017;26(Suppl 1):87.

16. Melmed S, Koenig R, Rosen C, Auchus R, Goldfine A. Williams Textbook of Endocrinology E-Book. 14th ed. Edinburgh: Elsevier Health Sciences; 2019.

17. Kogai T, Taki K, Brent G. Enhancement of sodium/iodide symporter expression in thyroid and breast cancer. Endocr Relat Cancer. 2006;13(3):797-826.

18. Kopp P. Human genome and diseases: review the TSH receptor and its role in thyroid disease. Cell Mol Life Sci. 2001;58(9):1301-22.

19. Xiao J, Yun C, Cao J, Ding S, Shao C, Wang L, et al. A pre-ablative thyroidstimulating hormone with 30-70 $\mathrm{mIU} / \mathrm{L}$ achieves better response to initial radioiodine remnant ablation in differentiated thyroid carcinoma patients. Sci Rep. 2021;11(1):1348.
20. Citterio CE, Targovnik HM, Arvan P. The role of thyroglobulin in thyroid hormonogenesis. Nat Rev Endocrinol. 2019;15(6):323-38.

21. Druetta L, Bornet $H$, Sassolas $G$, Rousset B. Identification of thyroid hormone residues on serum thyroglobulin: a clue to the source of circulating thyroglobulin in thyroid diseases. Eur J Endocrinol. 1999;140(5):457-67.

22. Brix K, Herzog V. Extrathyroidal release of thyroid hormones from thyroglobulin by $\mathrm{J774}$ mouse macrophages. J Clin Invest. 1994;93(4):1388-96.

23. Brix K, Wirtz R, Herzog V. Paracrine interaction between hepatocytes and macrophages after extrathyroidal proteolysis of thyroglobulin. Hepatology. 1997;26(5):1232-40.

24. Suzuki K, Mori A, Saito J, Moriyama E, Ullianich L, Kohn LD. Follicular thyroglobulin suppresses iodide uptake by suppressing expression of the sodium/iodide symporter gene. Endocrinology. 1999;140(11):5422-30.

25. Liu J, Liu R, Shen X, Zhu G, Li B, Xing M. The genetic duet of BRAF V600E and TERT promoter mutations robustly predicts loss of radioiodine avidity in recurrent papillary thyroid cancer. J Nucl Med. 2020;61(2):177-82.

\section{Publisher's Note}

Springer Nature remains neutral with regard to jurisdictional claims in published maps and institutional affiliations.
Ready to submit your research? Choose BMC and benefit from:

- fast, convenient online submission

- thorough peer review by experienced researchers in your field

- rapid publication on acceptance

- support for research data, including large and complex data types

- gold Open Access which fosters wider collaboration and increased citations

- maximum visibility for your research: over $100 \mathrm{M}$ website views per year

At BMC, research is always in progress.

Learn more biomedcentral.com/submissions 